\title{
Influence of Depression and Use of Alcohol and / or Tobacco by Parents in the Oral Health of Children with Disabilities
}

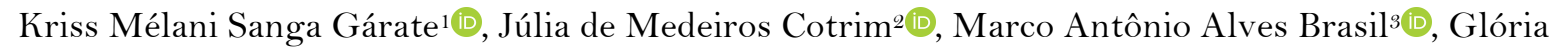 \\ Fernanda Barbosa de Araújo Castro10
}

\begin{abstract}
${ }^{1}$ Department of Pediatric Dentistry and Orthodontics, School of Dentistry, Federal University of Rio de Janeiro, Rio de Janeiro, RJ, Brazil.

${ }^{2}$ School of Dentistry, Federal University of Rio de Janeiro, Rio de Janeiro, RJ, Brazil.

${ }^{3}$ Department of Psychiatry and Medical Psychology Service, Clementino Fraga Filho University Hospital, Federal University of Rio de Janeiro, RJ, Brazil.
\end{abstract}

Correspondence: Glória Fernanda Barbosa de Araújo Castro, Rua Rodolpho Paulo Rocco 325, Cidade Universitária, Rio de Janeiro-Brazil, 21941-913. E-mail: gfbacastro@yahoo.com.br

Academic Editor: Alessandro Leite Cavalcanti

Received: 09 May 2020 / Review: 25 August 2020 / Accepted: 03 September 2020

How to cite: Gárate KMS, Cotrim JM, Brasil MAA, Castro GFBA. Influence of depression and use of alcohol and / or tobacco by parents in the oral health of children with disabilities. Pesqui Bras Odontopediatria Clín Integr. $2021 ; 21: e 0088$. https://doi.org/10.1590/pboci.2021.024

\begin{abstract}
Objective: To investigate the influence of parental depression and substance use in the oral health care of children with disabilities. Material and Methods: A cross-sectional study was conducted involving 151 children with disabilities and their parents/caregivers. To detect the presence of depression and alcohol or tobacco use, the parents/caregivers answered three questionnaires: two versions of the Patient Health Questionnaire (PHQ), AUDIT (Alcohol Use Disorders Identification Test), and the Fagerstrom Test for Nicotine Dependence (FTND). Then, the children with disabilities underwent oral examination to evaluate biofilm control, gingival condition and the dental carie index (decayed, missing, and filled teeth - dmft / DMFT). Results: There was a statistically significant association between tobacco use and dental caries in deciduous teeth $(\mathrm{p}=0.046)$. The children of smokers had six times greater need for dental treatment than that of non-smokers $(\mathrm{OR}=6.36 ; \mathrm{CI}=1.3-30.5)$. There was no statistically significant association between the oral health of the children with disabilities and parental alcohol consumption and depression $(\mathrm{p}>0.05)$. Children with medical condition had a higher need for dental treatment than children with intellectual disability ( $\mathrm{p}=0.003)$. Conclusion: Parental smoking habits increase dental caries in the deciduous teeth of children with disabilities, but parental depression and alcohol use do not influence the oral health of children with disabilities. Children with medical condition have more treatment needs than children with intellectual disability.
\end{abstract}

Keywords: Disabled Children; Oral Health; Tobacco; Depression; Caregivers. 


\section{Introduction}

Patients with special health care needs (SHCN) can be defined as those with impaired cognitive, behavioral, neuromuscular, genetic, congenital, systemic, or limiting disorders that require healthcare intervention and specialized services or programs [1]. According to the United Nations International Children's Emergency Fund (UNICEF), approximately 150 million children worldwide aged <18years live with disability [2], and are usually more susceptible to oral health problems. In fact, several studies have shown a high prevalence of caries, higher level of biofilm accumulation, worse gingival status, poor oral hygiene, and extensive unmet dental treatment needs in children and adolescents with disabilities [3].

On the other hand, the daily care of a child with disability often imposes a burden on parents or caregivers [4]. In this context, the parents of children with disabilities are more vulnerable to experiencing high levels of stress, anxiety and depression than parents with non-disabled children [5]. In fact, there is evidence for lower maternal capacity for self-care and care of their children when any form of mental health impairment is present [6]. This suggests that the presence of depressive symptoms can trigger secondary effects not only on the parents' health, but also on the child's general and oral health and care. Likewise, a previous study already suggests that maternal psychiatric disorders have a negative impact in the oral health of their children [7]. This may be even more worrying for parents of children with disabilities because they require more support, supervision, and special care in their daily activities. Oral health is no exception, as such patients often present oral pathologies specific to their condition or to other external factors [8]. There also appears to be a positive association between depression and alcohol and tobacco use in the general population $[9]$.

Consequently, our hypothesis is that a decline in parents' mental health could compromise their ability to provide care for their disabled children, which would be reflected in the poor oral health of the children.

Therefore, this paper aims to investigate if the presence of parental depression and substance use (alcohol and tobacco) might affect oral health care of children with disabilities, and document the dental needs according to the type of disability in this specific population.

\section{Material and Methods}

Study Design

A cross-sectional study was conducted with a non-probabilistic sample composed of 151 children and adolescents with disabilities aged 3-18 years of both sexes and their respective primary caregivers. In this study all children were patients who sought dental care at the Pediatric Clinic for Patients with Special Needs at a Brazilian University from September 2017 to November 2018. The subjects were divided into two groups according to type of disability: medical condition and intellectual disability, as defined by Salles et al. [10].

- Medical Condition (MD): This group includes patients with chronic diseases or syndromes without any neurological involvement example: cancer, diabetes, rheumatism, HIV, absence of limbs, hemophilia, cardiovascular disease, etc.

- Intellectual Disability (ID): The group was conformed by patients with intellectual disability by itself or in association to other conditions such as cerebral palsy, disorders of intellectual development, Down syndrome, etc. Autism spectrum disorder patients were included in this group because all the children in the present study had moderate or severe intellectual disabilities. 
Children with severe problems involving cooperation and management that prevented clinical examination were excluded from the study, as well as patients who used orthodontic appliances. Additionally, patients who lived in areas with frequent police operations and shootings were considered as living in risky areas.

Parental Depression and Substance Use Assessment

All interviews were conducted by a single interviewer previously trained by a psychiatrist. To assess the presence of depression symptoms in the primary caregiver, we used two versions of the Patient Health Questionnaire (PHQ): PHQ-2 and PHQ-9, via a face-to-face interview. In the first phase, screening was performed using the PHQ-2 this questionnaire consisting of two questions regarding the prevalent symptoms of depression for all caregivers. If the caregiver answered "yes" to at least one question, we applied the PHQ-9 that is a questionnaire that assesses the frequency of depressive symptoms in the last two weeks and severity level of depression. So, the PHQ-9 was used as a confirmatory instrument and contains nine items with scores of 0-3 for each question (maximum score, 27). A threshold score of 0-9 indicates the absence of depression, 1014 is considered mild depression, 15-19 indicates moderate depression, and 20-27 is classified as severe depression. Both questionnaires have been validated for the Brazilian population and used in public health programs [11].

Then, the Brazilian version of the Alcohol Use Disorders Identification Test (AUDIT), involving 10 questions related to the past 12 months, was applied to all caregivers to screen for hazardous and harmful alcohol use. The score ranges $0-40$, where $0-7$ indicates low risk or abstemious consumption, $8-15$ indicates risk of consumption, $16-19$ is considered harmful use or high-risk consumption, and $\geq 20$ indicates probable dependence [12].

Finally, a Portuguese adaptation of the Fagerstrom test for nicotine dependence (FTND) was used to detect nicotine dependence in all caregivers. The FTND is a 6-item scale with scores of $0-10$. The scores for nicotine dependence allow its classification in five levels: very low ( $0-2$ points), low (3-4 points), moderate (5 points), high (6-7 points), and very high (8-10 points) [13].

\section{Oral Health Assessment}

Before the intraoral clinical examinations, a calibration procedure was undertaken in 10 patients (who were not included in the study population) by a single examiner previously trained and calibrated. Subsequently, the intra-examiner Kappa concordance test was performed for the clinical parameters biofilm index, gingival condition, and caries index, revealing values $\geq 0.75$.

To evaluate their oral condition, all patients were examined using a mirror, explorer, gauze, and periodontal probe under artificial light. The criteria used for the biofilm index, gingival condition, and caries index were:

The quality and quantity of visible biofilm on the surfaces of the teeth - biofilm index proposed by Ribeiro et al. [14]. Biofilm was classified as thin when it could be identified only after drying the dental surface. A thick biofilm was one that was easily identified when it could be seen before the teeth were dried. To classify biofilm resistance to removal, a single lateral rubbing movement was performed with gauze (from distal to mesial or vice versa). The ease of removal was used to classify biofilm resistance to the dental surface. Children who scored o were considered to have excellent biofilm control, while scores 1 and 2 were considered 
satisfactory, because they represented thin and easily removed (immature) biofilm. However, scores of 3, 4, and 5 represented poor mechanical control due to the presence of thick and firmly adhered (mature) biofilm.

Gingival condition - index of Ainamo and Bay [15] - was scored as 0: presence of clinically healthy gingiva, without spontaneous or induced bleeding, after being probed; or 1: presence of bleeding after probing or with spontaneous bleeding.

Dental caries diagnosis was based on decayed, missing, and filled teeth (dmft, primary dentition; DMFT, permanent dentition) according to World Health Organization (WHO) [16] methodology and criteria. Based on dental caries, the children were classified with the presence or absence of carious lesions when $\mathrm{dmft} / \mathrm{DMFT}>0$ or $\mathrm{dmft} / \mathrm{DMFT}=0$, respectively.

In addition, a specific form for parents/ caregivers was applied in the form of an interview, which provided demographic, socioeconomic, and health information.

\section{Statistical Analysis}

The data were organized and analyzed using the Statistical Package for the Social Sciences (SPSS for Windows, version 20.0, SPSS Inc., Chicago, IL, USA). Descriptive and univariate statistics were performed to characterize the sample using the chi-square test for nominal variables and the Student t-test for numerical variables. Comparisons between the children with parents/caregivers with or without depression, alcohol abuse, and smoking habit according to the clinical variables (biofilm index, gingival condition, caries index) were performed using the chi-square test $\left(\chi^{2}\right)$, Fisher exact test, and we estimated the crude odds ratios $(\mathrm{OR})$ and their respective $95 \%$ confidence intervals (CI).

\section{Ethical considerations}

The present study was approved by the ethics committee of the Federal University of Rio de Janeiro (Process No. 68963517.8.0000.5257). The study was conducted in accordance with the Declaration of Helsinki. The parents/caregivers read and signed a statement of informed consent prior to the patients' participation. Caregivers with positive results for some psychiatric disorders were voluntarily referred to the psychiatry department for evaluation and treatment.

\section{Results}

From the 172 pairs of pediatric patients and their respective caregivers, 21 were excluded from the data analysis due to refusal to participate, non-cooperative behavior, use of fixed orthodontic appliance, or absence of the main caregiver. Thus, the final study sample comprised 151 patients, with a mean age of $10.52 \pm$ 3.94 years. Of the patients, $59.6 \%$ had ID; among them, the most prevalent was autism spectrum disorder (25.5\%), followed by Down syndrome (22.2\%) and disorders of intellectual development (21.1\%). The main caregivers were the parents (92.1\%), with a mean age of $41.9 \pm 9.8$ years. Most of the caregivers were living in risky areas (57\%) (Table 1$)$.

There was an association between the type of disability and presence of dental needs and caries experience in the deciduous teeth where the group of children with MC had more frequency of patients presenting dental needs $(59 \%)(\mathrm{p}=0.003)$ and caries experience $(65.1 \%)(\mathrm{p}=0.024)$ than ID group $(34.4 \%$ and $42.61 \%$, respectively). Also, the proportion of caries free children (dmft and/or DMFT=0) was significant lower in MC group (29.5\%) than in ID group (50.0\%) ( $\mathrm{p}=0.012)$ (Table 2). 
Table 1. Sample distribution according to sociodemographic, clinical and psychological characteristics.

\begin{tabular}{|c|c|c|}
\hline Variables & $\mathbf{N}$ & $\%$ \\
\hline \multicolumn{3}{|l|}{ Patients } \\
\hline \multicolumn{3}{|l|}{ Sex } \\
\hline Male & 99 & 65.6 \\
\hline Female & 52 & 34.4 \\
\hline \multicolumn{3}{|l|}{ Age (Years) } \\
\hline$<10$ & 65 & 43.0 \\
\hline$\geq 10$ & 86 & 57.0 \\
\hline \multicolumn{3}{|l|}{ Classification } \\
\hline Intellectual Disability (ID) & 90 & 59.6 \\
\hline Medical Condition (MC) & 61 & 40.4 \\
\hline \multicolumn{3}{|l|}{ Caregivers } \\
\hline \multicolumn{3}{|l|}{ Age (Years) } \\
\hline$<41$ & 69 & 45.7 \\
\hline$\geq 41$ & 82 & 54.3 \\
\hline \multicolumn{3}{|l|}{ Type of Caregiver } \\
\hline Parent & 139 & 92.1 \\
\hline Other & 12 & 7.9 \\
\hline \multicolumn{3}{|l|}{ Education Level } \\
\hline Elementary School & 64 & 42.4 \\
\hline High School & 70 & 46.4 \\
\hline Higher Education & 17 & 11.3 \\
\hline \multicolumn{3}{|l|}{ Lives in Risky Areas } \\
\hline Yes & 86 & 57.0 \\
\hline No & 65 & 43.0 \\
\hline \multicolumn{3}{|l|}{ Depression } \\
\hline Yes & 47 & 31.1 \\
\hline Mild & 18 & 11.9 \\
\hline Moderate & 20 & 13.2 \\
\hline Severe & 9 & 6.0 \\
\hline No & 104 & 68.9 \\
\hline \multicolumn{3}{|l|}{ Alcohol Consumption } \\
\hline Low Risk or Abstemious & 145 & 96.0 \\
\hline Risk of Consumption or Dependence & 6 & 4.0 \\
\hline \multicolumn{3}{|l|}{ Tobacco Use } \\
\hline Yes & 11 & 7.3 \\
\hline Very Low & 1 & 0.7 \\
\hline Low & 2 & 1.3 \\
\hline Medium & 1 & 0.7 \\
\hline High & 7 & 4.6 \\
\hline No & 140 & 92.7 \\
\hline
\end{tabular}

Table 2. Carie experience and dental need according to type of disability.

\begin{tabular}{|c|c|c|c|c|}
\hline \multirow[b]{2}{*}{ Variables } & & \multicolumn{2}{|c|}{ Patients } & \multirow[b]{2}{*}{ p-value } \\
\hline & & $\begin{array}{l}\text { Intellectual Disability } \\
\qquad \mathrm{N}(\%)\end{array}$ & $\begin{array}{c}\text { Medical Condition } \\
\text { N }(\%)\end{array}$ & \\
\hline \multirow[t]{2}{*}{ Need for Dental Treatment } & Yes & $31(34.4)$ & $36(59.0)$ & $0.003 *$ \\
\hline & No & $59(65.6)$ & $25(41.0)$ & \\
\hline \multirow{2}{*}{ Caries Experience in Deciduous Teeth } & Yes & $26(42.6)$ & $28(65.1)$ & $0.024 *$ \\
\hline & No & $35(57.4)$ & $15(34.9)$ & \\
\hline \multirow[t]{2}{*}{ Caries Experience in Permanent Teeth } & Yes & $25(30.5)$ & $22(40.0)$ & 0.250 \\
\hline & No & $57(69.5)$ & $33(60.0)$ & \\
\hline \multirow[t]{2}{*}{ Total Caries Experience } & Yes & $45(50.0)$ & $43(70.5)$ & $0.012^{*}$ \\
\hline & No & $45(50.0)$ & $18(29.5)$ & \\
\hline
\end{tabular}

*Represent statistical significant p-values $(\mathrm{p}<0.05)$. 
Up to $31.1 \%$ of the caregivers had depression. Among the caregivers with depressive symptoms $(\mathrm{n}=47)$, most $(42.5 \%)$ had moderate depression. Regarding alcohol consumption, $96 \%$ of caregivers $(n=145)$ were low risk or abstemious, and only 7.3\% $(\mathrm{n}=11)$ used tobacco. Among the caregivers who were smokers, $63.6 \%(n=7)$ had a high degree of nicotine dependence (Table 1). In addition, the caregivers' education levels were not associated with the level of depression $(\mathrm{p}=0.297)$.

The bivariate analysis results (Table 3) showed that the average dmft was greater in children whose parents used tobacco $(\mathrm{p}=0.046)$. Thus, children of caregivers who smoke are eight times more likely to have deciduous teeth caries than the children of non-smokers $(\mathrm{OR}=8.52$; $\mathrm{CI}=1.03-70.8)$. There was also a significant positive correlation between dental treatment needs and caregivers' tobacco use $(p=0.009)$. This strong association indicates that children of smokers also have six times greater need for dental treatment than that of non-smokers $(\mathrm{OR}=6.36 ; \mathrm{CI}=1.3-30.5)$. There were no statistically significant associations with the caries index for depression and alcohol abuse.

Table 3. Association between caregivers' depression, alcohol consumption, and tobacco use and children's oral health.

\begin{tabular}{|c|c|c|c|c|}
\hline \multirow[b]{2}{*}{ Variables } & \multicolumn{2}{|c|}{ Depression } & \multirow[b]{2}{*}{ p-value } & \multirow[b]{2}{*}{ OR $(95 \% C I)$} \\
\hline & $\begin{array}{c}\text { Yes } \\
\text { N (\%) }\end{array}$ & $\begin{array}{c}\text { No } \\
\text { N (\%) }\end{array}$ & & \\
\hline \multicolumn{5}{|l|}{ Biofilm Control } \\
\hline Excellent/Satisfactory & $37(78.7)$ & $72(69.2)$ & $0.228^{\dagger}$ & $1.64(0.7-3.7)$ \\
\hline Poor & $10(21.3)$ & $32(30.8)$ & & \\
\hline \multicolumn{5}{|l|}{ Gingival Bleeding } \\
\hline Yes & $13(27.7)$ & $33(31.7)$ & $0.615^{\dagger}$ & $0.82(0.3-1.7)$ \\
\hline No & $34(72.3)$ & $71(68.3)$ & & \\
\hline Dmft - Mean (SD) & $1.78(2.55)$ & $2.31(3.32)$ & $0.428+$ & $0.74(0.3-1.7)$ \\
\hline DMFT - Mean (SD) & $1.15(2.04)$ & $0.80(1.51)$ & $0.276_{+}^{+}$ & $1.15(0.5-2.4)$ \\
\hline \multicolumn{5}{|l|}{ Dental Treatment Needs } \\
\hline Yes & $22(46.8)$ & $45(43.3)$ & $0.685^{\dagger}$ & $1.15(0.5-2.3)$ \\
\hline No & $25(53.2)$ & $59(56.7)$ & & \\
\hline Total & 47 & 104 & & \\
\hline \multicolumn{5}{|c|}{ Alcohol Consumption } \\
\hline & Consumption of Risk & Low Risk or & & \\
\hline & or Dependence & Abstemious & & \\
\hline \multicolumn{5}{|l|}{ Biofilm Control } \\
\hline Excellent/Satisfactory & $4(66.7)$ & $105(72.4)$ & $0.758 \uparrow$ & $0.76(0.1-4.3)$ \\
\hline Poor & $2(33.3)$ & $40(27.6)$ & & \\
\hline \multicolumn{5}{|l|}{ Gingival Bleeding } \\
\hline Yes & $3(50.0)$ & $43(29.7)$ & $0.289^{\dagger}$ & $2.37(0.4-12.2)$ \\
\hline No & $3(50.0)$ & $102(70.3)$ & & \\
\hline Dmft - Mean (SD) & $2.25(2.22)$ & $2.14(3.14)$ & $0.945^{+}$ & $2.88(0.2-28.6)$ \\
\hline DMFT - Mean (SD) & $0.80(0.84)$ & $0.91(1.71)$ & $0.888_{+}^{+}$ & $3.00(0.4-18.6)$ \\
\hline \multicolumn{5}{|l|}{ Dental Treatment Needs } \\
\hline Yes & $2(33.3)$ & $54(44.8)$ & $0.579^{\uparrow}$ & $0.61(0.1-3.4)$ \\
\hline No & $4(66.7)$ & $80(55.2)$ & & \\
\hline Total & 6 & 145 & & \\
\hline \multicolumn{5}{|c|}{ Tobacco Use } \\
\hline & Yes & No & & \\
\hline \multicolumn{5}{|l|}{ Biofilm Control } \\
\hline Excellent/Satisfactory & $8(72.7)$ & $101(72.1)$ & $0.967+$ & $1.03(0.2-4.0)$ \\
\hline Poor & $3(27.3)$ & $39(27.9)$ & & \\
\hline \multicolumn{5}{|l|}{ Gingival Bleeding } \\
\hline Yes & $2(18.2)$ & $44(31.4)$ & $0.358^{\dagger}$ & $0.48(0.1-2.3)$ \\
\hline No & $9(81.8)$ & $96(68.6)$ & & \\
\hline Dmft - Mean (SD) & $4.11(4.05)$ & $1.96(2.95)$ & $0.046+^{+*}$ & $8.52(1.03-70.8)$ \\
\hline
\end{tabular}




\begin{tabular}{|c|c|c|c|c|}
\hline DMFT - Mean (SD) & $0.55(1.04)$ & $0.94(1.73)$ & $0.463^{+}$ & $0.69(0.1-2.7)$ \\
\hline \multicolumn{5}{|c|}{ Dental Treatment Needs } \\
\hline Yes & $9(81.8)$ & $58(41.4)$ & $0.009^{\uparrow *}$ & $6.36(1.3-30.5)$ \\
\hline No & $2(18.2)$ & $82(58.6)$ & & \\
\hline Total & 11 & 140 & & \\
\hline
\end{tabular}

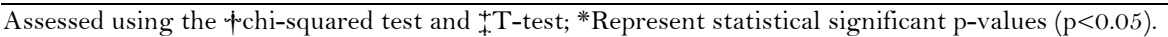

\section{Discussion}

Children with disabilities have an increased risk for oral diseases, such as dental caries, and this has been attributed to disability-related factors such as diet, inadequate oral hygiene, and lack of cooperation [17]. However, few studies have considered psychiatric disorders such as depression and substance use (tobacco and alcohol) in caregivers as possible contributing factors for poor oral health of children with disabilities.

Previous authors did not find any significant association between stress scores and prevalence of early childhood caries [18]. In contrast, more recent studies have found a correlation between depression in mothers and caries in disabled [19] and non-disabled children [7]. Here, we did not observe a significant association between depression in caregivers and the patients' dmft/DMFT scores. This could be due to the fact that, unlike the previous studies, our total sample was formed by regular patients at the pediatric dental clinic for children with special needs, who receive specialized dental care according to individual need.

On the other hand, there is a strong tendency for parents to ignore their personal life, needs, social relationships, and dreams, putting as the main focus of attention all of their child's needs, including therapeutic treatments [20], which was demonstrated during the interviews:

"My life revolves around her."

"I do not have time to be sad or depressed I have to take care of her."

"I once thought about suicide but then I think about her and how much she needs me."

Therefore, our results suggest that parents can sometimes reframe situations that require great effort, such as their child's disability, into a positive experience, as described by Beighton and Wills [21], where parents reported that their child's disability contributed to their personal and spiritual growth as well as to a greater purpose in life, which could help fight depressive symptoms.

We also did not find a statistically significant relationship between parental alcohol consumption and the oral health of children with disabilities. In the literature review no previous study was found. This could be due to the little incidence of high-risk alcohol consumption among caregivers. However, the present study shows that caregivers' smoking habits are associated with increased prevalence of dental caries in deciduous teeth but not in permanent teeth. Moreover, they were also associated with greater dental treatment needs in children with disabilities. These results are in agreement with previous studies. A significant association between parental smoking behavior and caries experience in children has been reported previously [22]. Other authors have concluded that there is an association between secondhand smoke and caries in primary teeth, but no association with permanent teeth [23]. In addition, Arora et al. [24] found a positive, although statistically non-significant, association between environmental cadmium exposure (a toxic component of tobacco) with dental caries in deciduous teeth, but not in permanent teeth. Some of the possible hypotheses for explaining these findings are that exposure to tobacco smoke and its many chemicals could compromise the child's immune system [25]. Additionally, environmental tobacco smoke contains the same toxins as that inhaled by the active smoker but in lower doses; therefore, the same mechanisms that affect active smokers could affect the oral health of passive smokers [26]. In these conditions, the deciduous teeth would be more 
vulnerable than the permanent teeth because they have much thinner enamel and are less mineralized than the permanent teeth [27].

On the other hand, our study reflects a poor oral health status of children with disabilities whose parents were tobacco users, suggesting that the abuse of this substance not only affects the smoker but also causes adverse effects on the oral health care of their children, being even more worrying in the case of children with disabilities due to the fact that they require more support in their daily activities and their oral health often lie in the hands of their parents who are responsible for motivating, directing, supervising and in many occasions of perform your oral hygiene however more researches are necessaries to elucidate this point.

In addition, we want to highlight the importance of pediatric dentistry as part of a multidisciplinary team to detect parents with a psychological problem and to be able to refer them to specialists to receive adequate medical and emotional support.

The present study also provides further evidence that dental treatment needs may be associated with the child's disability type. Our results indicate that patients with MC have greater dental treatment needs than those with ID; this may be related to several factors, such as state of immunosuppression [28], medications [29] likewise, this could also be due to the fact that parents of children with MC pay more attention to the main disease of their children, leaving oral health in a secondary plan.

One limitation of this study is that no radiographs were obtained; therefore, proximal caries was probably not identified. Other limiting factors were that aspects such as salivary parameters, influence of regular medication and diet were not evaluated in the present study. Furthermore, these data cannot be extrapolated to the entire population of children with disabilities, but represent children with disabilities periodically assisted by a dental health institution. Therefore, these observations point to the need to conduct longitudinal studies and to use larger samples to verify the present data.

Finally, we consider psychiatric disorders and substance abuse as possible distal factors, that is to say, not directly affect the health of the child, but they could act through mediators such as parents/caregivers who take control of their children's oral health at home. Therefore, it would be plausible to describe the presence of depression in caregivers and the use of substances such as tobacco and alcohol by caregivers as possible distal risk factors for the oral health of children with disabilities, which is a step forward in the expanding understanding of the interaction of these factors in addition to the biological causes and other causes directly related to caries that have already been widely studied.

\section{Conclusion}

Our results reveal that parental smoking appears to have a detrimental effect on oral health care of children with disabilities, showing a high dmft index and treatment needs in the children. Therefore, parents with smoking habits should be advised on the risk behaviors that could affect their children's oral health. Depression and alcohol consumption in caregivers did not influence the oral health of children with disabilities. Children with MC have more treatment needs than children with ID. Dentists should guide caregivers about the important role they play in the oral and general health of their children with disabilities.

\section{Authors' Contributions}

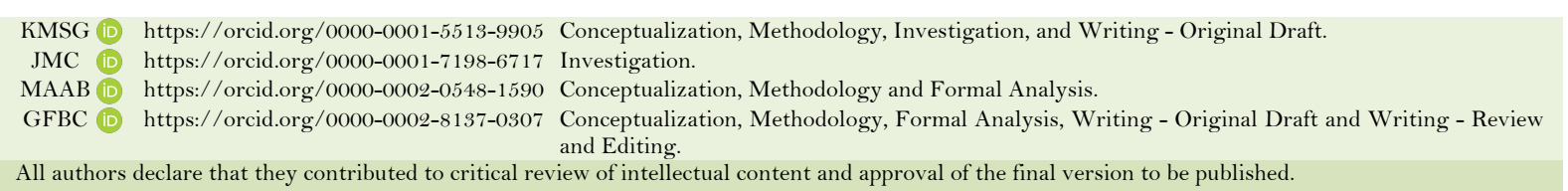

All authors declare that they contributed to critical review of intellectual content and approval of the final version to be published. 


\section{Financial Support}

This study was supported by the Coordenação de aperfeiçoamento de Pessoal de Nivel Superior- Brasil (CAPES) - Finance Code oo1.

\section{Conflict of Interest}

The authors declare no conflicts of interest.

\section{Acknowledgements}

The authors would like acknowledging the cooperation rendered by the caregivers and children who took part in the study.

\section{Data Availability}

The data used to support the findings of this study can be made available upon request to the corresponding author.

\section{References}

[1] American Academy of Pediatric Dentistry. Council on Clinical Affairs. Guideline on management of dental patients with special health care needs. Pediatr Dent 2012; 34(5):160-5.

[2] The United Nations Children's Fund. The State of the World's Children 2006: Excluded and Invisible. New York UNICEF; 2006. 143p.

[3] Zhou N, Wong HM, Wen YF, Mcgrath C. Oral health status of children and adolescents with intellectual disabilities: a systematic review and meta-analysis. Dev Med Child Neurol 2017; 59(10):1019-26. https://doi.org/10.1111/dmcn.13486

[4] Santos MT, Biancardi M, Guare RO, Jardim JR. Caries prevalence in patients with cerebral palsy and the burden of caring for them. Spec Care Dent 2010; 30(5):206-10. https://doi.org/10.1111/j.1754-4505.2010.00151.x

[5] Tufail N, Batool S, Rehman A. A comparative research on disabled and non-disabled children's mothers in terms of depression and anxiety prevalence. Indo Am J P Sci 2018; 5(6):5724-31. https://doi.org/10.5281/zenodo.1298687

[6] Dang AT, Ho M, Kroenke K, Grupp-Phelan J. Maternal somatic symptoms, psychosocial correlates, and subsequent pediatric emergency department use. Pediatr Emerg Care 2013; 29(2):170-4. https://doi.org/10.1097/PEC.0b013e3182809a10

[7] dos Santos Pinto G, de Ávila Quevedo L, Correa MB, Azevedo MS, Goettems ML, Pinheiro RT, et al. Maternal depression increases childhood dental caries: a cohort study in Brazil. Caries Res 2017; 51(1):17-25. https://doi.org/10.1159/000449040

[8] Diéguez-Pérez M, de Nova-García M-J, Mourelle-Martínez MR, Bartolomé-Villar B. Oral health in children with physical (Cerebral Palsy) and intellectual (Down Syndrome) disabilities: systematic review I. J Clin Exp Dent 2016; 8(3):e337-343. https://doi.org/10.4317/jced.52922

[9] Khan M, Monaghan M, Klein N, Ruiz G, John AS. Associations among depression symptoms with alcohol and smoking tobacco use in adult patients with congenital heart disease. Congenit Heart Dis 2015; 10(5):E243-E249. https://doi.org/10.1111/chd.12282

[10] Salles PS, Tannure PN, Oliveira R, de Souza IPR, Portela MB, Castro GF. Dental needs and management of children with special health care needs according to type of disability. J Dent Child 2012; 79(3):165-9.

[11] de Lima Osório F, Vilela Mendes A, Crippa JA, Loureiro SR. Study of the discriminative validity of the PHQ-9 and PHQ-2 in a sample of Brazilian women in the context of primary health care. Perspect Psychiatr Care 2009; 45(3):2 16-27. https://doi.org/10.1111/j.1744-6163.2009.00224.x

[12] Babor TF, Higgins-Biddle JC, Saunders JB, Monteiro MG. AUDIT: The Alcohol Use Disorders Identification Test: Guidelines for Use in Primary Health Care. 2nd ed. Geneva: World Health Organization; 2001.

[13] Meneses-Gaya IC, Zuardi AW, Loureiro SR, Crippa JA. Psychometric properties of the Fagerström test for nicotine dependence. J Bras Pneumol 2009; 35(1):73-82. https://doi.org/10.1590/s1806-37132009000100011

[14] Ribeiro AA, Portela M, Souza IP. Relation between biofilm, caries activity and gingivitis in HIV+ children. Pesqui Odontol Bras 2002; 16(2):144-50. https://doi.org/10.1590/S1517-74912002000200009

[15] Ainamo J, Bay I. Problems and proposals for recording gingivitis and plaque. Int Dent J 1975; 25(4):229-35.

[16] World Health Organization. Oral Health Surveys: Basic Methods. 5th ed. Geneva: World Health Organization; 1997.

[17] Mandić J, Jovanović S, Mandinić Z, Ivanović M, Kosanović D, Biljana M, et al. Oral health in children with special needs. Vojnosanit Pregl 2018; 75(00):675-81. https://doi.org/10.2298/VSP160707372M

[18] Jabbarifar SE, Ahmady N, Sahafian SAR, Samei F, Soheillipour S. Association of parental stress and early childhood caries. Dent Res J 2009; 6(2):65-70.

[19] D'Alessandro G, Cremonesi I, Alkhamis N, Piana G. Correlation between oral health in disabled children and depressive symptoms in their mothers. Eur J Paediatr Dent 2014; 15(3):303-8. https://doi.org/10.1037/11877-005 
[20] Ljubešić M. Roditelji djece s teškoćama u razvoju i usluge za podršku roditeljstvu. Zagreb: UNICEF; 2013. [In Croatian]

[21] Beighton C, Wills J. Are parents identifying positive aspects to parenting their child with an intellectual disability or are they just coping? A qualitative exploration. J Intellect Disabil 2017; 21(4):325-45. https://doi.org/10.1177/1744629516656073

[22] Phillips M, Masterson E, Sabbah W. Association between child caries and maternal health-related behaviours. Community Dent Health 2016; 33(2):133-7. https://doi.org/10.1922/CDH_3801Phillips05

[23] Aligne CA, Moss ME, Auinger P, Weitzman M. Association of pediatric dental caries with passive smoking. JAMA 2003; 289(10):1258-64. https://doi.org/10.1001/jama.289.10.1258

[24] Arora M, Weuve J, Schwartz J, Wright RO. Association of environmental cadmium exposure with pediatric dental caries. Environ Health Perspect 2008; 1 16(6):82 1-5. https://doi.org/10.1289/ehp.10947

[25] Kum-Nji P, Meloy L, Herrod HG. Environmental tobacco smoke exposure: prevalence and mechanisms of causation of infections in children. Pediatrics 2006; 117(5):1745-54. https://doi.org/10.1542/peds.2005-1886

[26] Tanaka K, Miyake Y, Arakawa M, Sasaki S, Ohya Y. Household smoking and dental caries in schoolchildren: the Ryukyus Child Health Study. BMC Public Health 2010; 10:335. https://doi.org/10.1 186/1471-2458-10-335

[27] De Menezes Oliveira MA, Torres CP, Gomes-Silva JM, Chinelatti MA, De Menezes FC, Palma-Dibb RG, et al. Microstructure and mineral composition of dental enamel of permanent and deciduous teeth. Microsc Res Tech 2010; 73(5):572-7. https://doi.org/10.1002/jemt.20796

[28] Foster H, J Fitzgerald. Dental disease in children with chronic illness. Arch Dis Child 2005; 90(7):703-8. https://doi.org/10.1136/adc.2004.058065

[29] Nirmala SV, Popuri VD, Chilamakuri S, Nuvvula S, Veluru S, Minor Babu MS. Oral health concerns with sweetened medicaments: Pediatricians' acuity. J Int Soc Prev Community Dent 2015; 5(1):35-9. https://doi.org/10.4103/22310762.151973 